\title{
correspondence
}

\section{GMAG should look to NIH}

SIR,- I write to enquire whatever happened to the public debate on changes in the regulations for genetic manipulation experiments? The notion of rationalising genetic manipulation containment by measuring the risk in each experiment was put forward in the columns of Nature last month. A public meeting was promised and was indeed convened in London on 21 December. This meeting could be called neither public nor a debate and achieved little or nothing. Views were expressed by members of GMAG, both on the panel and in the audience, that revealed strong political polarisation but little in the way of scientific evidence supporting either the present guidelines or possible alternatives. From the body of the meeting the only view which came across strongly and repeatedly was the indignation of many scientists at the classification of experiments involving the manipulation of $E$. coli DNA in E. coli. A host of important questions concerning the proposed new systems of evaluating the necessary containment for particular genetic manipulation experiments were not raised at this meeting. Even where one or two points were raised, time for discussion was inadequate. It is safe to conclude that there has been no proper forum for public debate.

By contrast to events in this country we have the example of the way in which the NIH guidelines have recently been revised in the US. Irrespective of whether one agrees or disagrees with the new NIH guidelines one must admire the broadly based public debate the informed political comment and the rapidity of the process of modification of the proposals in response to debate and comment. Moreover the whole process, up to and including publication of the new guidelines, is freely available in the Federal Register. We could, to our advantage, learn from those events.

The need to change the genetic manipulation guidelines in Britain is just as pressing as was the need in the US. Our present guidelines are illogically restrictive. The levels of containment imposed upon genetic manipulation experiments in Britain have from the beginning exceeded those required in the US. This difference taken together with the lack of availability of physical containment facilities in this country has meant a severe handicap for British work with systems designated as requiring high containment. The introduction of the new NIH guidelines has widened the gap between containment required in the US and that required in Britain to such an extent that it is now impractical to continue a wide range of genetic manipulation experiments in this country. On a global basis it perhaps matters not whether Britain is involved in genetic manipulation research. For
Britain however, the consequences of missing out on a revolution in biological technology and in losing a generation of the best young scientists who wish to be trained in that area will be dire. If the guidelines for genetic manipulation experiments in Britain are to be changed then the change must be effected rapidly. There is no sign of swift action on the Brenner initiative nor of an informed debate. Looking again at the global picture, should we be so insular as to think that we should repeat a process which has been painstakingly conducted in the US. Biological risks by their very nature do not respect national boundaries. We would be wise to look carefully at the guidelines accepted by the majority of scientists working with genetic manipulation and by the nation within which they carry out their work. I think that we could, without endangering either workers in the field or the public at large, adopt the philosophy of the NIH guidelines and indeed, with certain modifications to British conditions, the letter of those guidelines. The NIH guidelines remain largely empirical but they are based on extensive experience. In science we do not look at national origins in evaluating ideas or experimental results. I trust that in this case that neither national pride nor political ideology will prevent serious consideration of the $\mathrm{NIH}$ guidelines as a suitable model for genetic manipulation work in Britain. Yours faithfully,

Alan R. Williamson

Institute of Biochemistry.

University of Glasgow, UK.

\section{The status of safety officers}

SIR,--In your editorial "Smallpox: ignorance is never bliss" (11 January, page 75), you advocate a new breed of medically qualified safety officers, universally respected. Whilst I agree that a properly professional approach to laboratory safety is required, I suggest it would be inappropriate to require medical qualifications for safety officers.

Your suggestion that "a safety officer should always be a doctor" is ill considered. The example upon which you seem to have based the proposal is misleading. Dr Mark Darlow was in a unique position at MRE Porton. He was successful because he was the right person for that particular job.

There has been a predictable reaction in the press to the whole sad saga of Birmingham. We must use the impetus of public concern to improve our scientific safety position. It is undeniable that our scientific safety has left much to be desired and that many of its practitioners have been ineffectual. We should introduce a system for recognition of professional safety officers combined with a worthwhile career structure to encourage people in whom both the general public and the scientific community can feel confident.

The status of safety officers should be assured by their employers-who are ultimately responsible for safety under the Health and Safety at Work Act (1974). Safety officers are charged with obligations to ensure the observance of statutory regulations and safety codes. They should work in conjunction with a safety committee constituted to represent all groups of employees from academic staff to ancillary staff.

Thus it will only be when properly qualified and professionally accountable safety officers are employed and given the opportunity and incentive to carry out research and to get on with the job of safety in science, that we could feel that we have learned the lessons so apparent in this latest tragedy. Yours faithfully,

M. R. BAILEY

National Institute for Medical Research, London, UK.

\section{Reason not ruction}

SiR,-In your issue of 21/28 December, page 753 , Dr Kenneth Mellanby quotes a secular hymn from a Socialist Sunday School in Glasgow in the 1920s:

"By nature not nurture we'll rise to the skies

The means of production we'll nationalise."

This is curiously like the refrain from a revue song by A. P. Herbert, which I quote from memory:

"By reason not ruction we'll soar to the skies

The means of production we'll nationalise

And rapture surprising we'll bring within range

By nationalising the means of exchange."

I prefer APH's version. Yours faithfully,

O. MAYO

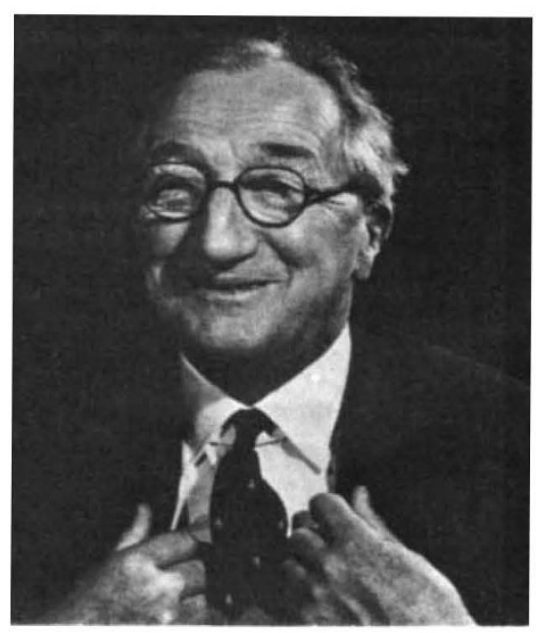

A. P. Herbert: British humourist 